\title{
A construção dos conceitos de comunidade, identidade e memória a partir da prática da comunicação comunitária
}

\section{Camila Escudero}

Universidade Metodista de São Paulo, Programa de Pós-Graduação em Comunicação, São Bernardo do Campo, SP, Brasil

ORCID: 0000-0002-9399-1207

\section{Lucia Caetano}

Universidade Metodista de São Paulo, Programa de Pós-Graduação em Comunicação, São Bernardo do Campo, SP, Brasil

\section{Eduardo Reina}

Universidade Metodista de São Paulo, Programa de Pós-Graduação em Comunicação, São Bernardo do Campo, SP, Brasil

\section{Resumo}

Este artigo tem o objetivo de verificar como se configuram os conceitos de comunidade, identidade e memória a partir de iniciativas práticas de mídia comunitária. A proposta parte de uma perspectiva inversa à lógica comumente vista: no lugar de trazer conceitos para explicar realidades empíricas, procura verificar como os conceitos se constroem a partir das experiências. Para isso, propomos uma Análise de Conteúdo, de abordagem qualitativa, sobre um corpus composto por 30 artigos acadêmicos publicados em eventos científicos e livros da área da Comunicação Social, que registram experiências de mídia comunitária. Entre os principais resultados, destacamos que as experiências cotidianas de uma comunidade "traduzidas" por seus veículos, bem como pela prática de produção desses veículos, revelam uma dimensão de ordem afetiva, vinculativa, identitária e histórica do grupo envolvido, na qual conceitos de comunidade, identidade e memória ganham outros contornos, funções e evidências.

\section{Palavras-chave}

Mídia comunitária; Memória; Identidade; Comunidade; Comunicação Social 


\section{Introdução}

Os estudos científicos de mídia comunitária costumam trazer os conceitos de comunidade e identidade, entre tantos outros, para o campo da Comunicação Social em ricos debates e diálogos que favorecem a compreensão da práxis comunicacional. Quando utilizados, ambos envolvem definições amplas e complementares entre si, que favorecem a visibilidade da realidade sociocultural envolvida, revelando particularidades de laços e vínculos entre sujeitos e/ou entre sujeitos e territórios, natureza e história, além de indicar alternativas à concentração do poder midiático que estrutura os meios de comunicação na contemporaneidade.

Dentro do campo da Comunicação no Brasil, os estudos sobre mídia comunitária começaram a surgir no fim da década de 1980, a partir da necessidade de se registrar e analisar, cientificamente, a realidade empírica das práticas midiáticas que davam voz e vez aos sujeitos excluídos dos processos convencionais de comunicação, produzindo valor social, cultural e político. Nesse sentido, ganharam amplitude conceitual, sendo reconhecidos, também, por nomenclaturas como comunicação comunitária, alternativa, popular, dialógica, participativa, radical, libertadora, de minorias, contra-hegemônica, entre outras.

Muito inspirados nas propostas da pedagogia libertadora de Paulo Freire ou mesmo no conceito de contra-hegemonia a partir das ideias de Gramsci e Raymond Williams, os estudos sobre mídia comunitária destacam a resistência dos atores envolvidos e a luta no desenvolvimento de projetos em um contexto que envolve conceitos como o de democracia e o de cidadania. Ao longo do tempo, porém, percebeu-se que esses mesmos projetos são responsáveis por enfatizar a memória do grupo envolvido e seus vínculos, fortalecendo-o como comunidade e construindo, a partir das identidades envolvidas, a história organizativa do grupo.

Assim, o presente artigo tem o objetivo de verificar como, a partir de iniciativas práticas de mídia comunitária, se configuram os conceitos de comunidade, identidade e memória. A proposta é inverter a lógica: não trazendo os três conceitos para explicar processos de mídia comunitária e propiciar o debate sobre o tema dentro do campo da Comunicação, mas, a partir da área comunicacional, indicar como esses conceitos são utilizados e construídos. 
Partimos da hipótese de que tal análise enfatizará a necessária inversão de valor do campo da Comunicação. Não se trata de resumir a cientificidade da nossa área a outras áreas que tenham interesse em aplicar a Comunicação em suas realidades, mas sim como lembra Sodré (2014), a Comunicação assumir seu protagonismo essencial às relações humanas em qualquer campo do saber. Para atingir nosso objetivo, propomos uma Análise de Conteúdo (AC) de abordagem qualitativa. Nas palavras de Krippendorff (1990, p. 28, tradução nossa), a AC "é uma técnica de investigação destinada a formular, a partir de certos dados, inferências reproduzidas e válidas que possam aplicar-se a seu contexto". A análise foi organizada de acordo com o que Bardin (1977) chamou de "pólos cronológicos": (1) préanálise; (2) exploração do material; e (3) tratamento dos resultados, interferência e interpretação.

Nosso corpus de pesquisa reúne artigos científicos publicados em 2016 e 2017 nos anais dos dois principais congressos científicos brasileiros da área da Comunicação, entre eles, o Congresso Brasileiro de Ciências da Comunicação promovido pela Intercom Sociedade Brasileira de Estudos Interdisciplinares da Comunicação desde 1997; e, o Encontro Anual da Compós, promovido pela Associação Nacional dos Programas de PósGraduação em Comunicação, fundada em 1991. Contempla, ainda, artigos publicados em coletâneas organizadas por duas pesquisadoras brasileiras referências na área: Cicilia Peruzzo e Raquel Paiva, respectivamente: Comunicação popular, comunitária e alternativa no Brasil: Sinais de resistência da construção de cidadania de 2015 e O retorno da comunidade: Os novos caminhos do social de 2007.

Em um primeiro momento, de pré-análise, fizemos a leitura prévia de todos os artigos publicados nos anais e livros indicados no parágrafo acima. A partir de então, selecionamos os trabalhos que registraram alguma experiência prática de mídia comunitária (independentemente do foco: analítico, historiográfico, epistemológico). No total, foram selecionados 30 artigos. Em seguida, na exploração do material, submetemos todos os artigos a um protocolo de análise (explicitado no item 4 deste artigo), em uma tentativa de fornecer, por condensação, uma representação simplificada dos dados brutos, obedecendo a critérios como: exclusão mútua, homogeneidade, pertinência, objetividade, entre outros.

A última fase foi o tratamento dos resultados, inferências e interpretação. Soma-se a isso, uma breve revisão de literatura - baseada em Stumpf (2011) - sobre os conceitos centrais deste artigo: comunidade, identidade, memória e mídia comunitária. 


\section{Comunidade, identidade e memória: correlações}

Há tempos que a comunidade é objeto de estudo da área científica, em especial das Ciências Sociais. Um dos pioneiros no tratamento do assunto é Ferdinand Tönnies (18551936) - até os dias de hoje, revisitado pelas pesquisas da temática. As ideias desse autor percorrem, basicamente, os marcos conceituais que lidam com os níveis mais elementares das relações sociais, sendo sua principal contribuição a distinção clássica entre dois tipos básicos de organização social: a comunidade (Gemeinschaft) e a sociedade (Gesellschaft).

Para Tönnies (1973), as relações sociais são criações da vontade humana. 0 modelo explicativo do autor coloca a "vontade essencial" (ou natural) e a "vontade arbitrária" como elementos fundamentais na determinação da configuração das relações sociais, apontando os princípios de organização institucional, moral e morfológica dos grupos humanos. Em linhas gerais, a primeira se constitui uma tendência básica do sujeito, instintiva, espontânea, orgânica e que impulsiona a atividade humana. Já a segunda é uma forma deliberada, reflexiva e finalista, capaz de determinar a atividade humana a partir de regras estabelecidas em um plano contratual, implicando relações de poderes e interesses.

Assim, de acordo com Tönnies (1973), o tipo de vontade predominante tem, por sua vez, um papel simbólico e imaginário precioso na construção das representações coletivas do grupo. Um corpo comunitário existiria muito antes da constituição social dos indivíduos e seus fins, ainda que isso não implique sua restrição a condições sociogenéticas: “[...] a comunidade é a vida comum, verdadeira e durável; a sociedade é somente passageira e aparente" (TÖNNIES, 1973, p. 98).

A partir de então, Tönnies (1973) propõe uma "teoria da comunidade", que seria estimulada pelas raízes territoriais (o país, a região, a aldeia), pelos laços sanguíneos (relação vertical: pais e filhos) e pelas afinidades (relação horizontal: irmãos e vizinhos):

De fato, a unidade e a possibilidade de uma comunidade das vontades humanas se apresentam, em primeiro lugar e de maneira mais imediata, nos laços de sangue; em segundo lugar, na aproximação espacial e, finalmente, para homens, na aproximação espiritual. É nesta classificação, portanto, que devemos procurar as raízes de todas as relações (associações). Daí nós construímos as leis principais da comunidade. (TÖNNIES, 1973, p. 104).

Porém, observa o autor: se na comunidade, os homens permanecem unidos apesar de todas as separações, na sociedade permanecem separados não obstante todas as uniões. 
Nesse sentido, apresenta a "teoria da sociedade". Resumidamente, trata-se de um grupo de homens que, "vivendo e permanecendo de maneira pacífica uns aos lados dos outros, como na comunidade, não estão organicamente unidos mas, organicamente separados" (TÖNNIES, 1973, p. 106):

\begin{abstract}
A sociedade, portanto, pela convenção e pelo direito de um agregado, é compreendida como uma soma de indivíduos naturais e artificiais, cujas vontades e domínios se encontram em associações numerosas, mas que permanecem, entretanto, independentes uns dos outros e sem ação interior recíproca. (TÖNNIES, 1973, p. 113).
\end{abstract}

Max Weber (1864-1920) é outro intelectual considerado um dos pioneiros nos estudos sistematizados sobre comunidade. 0 autor reconhece esse modelo proposto por Ferdinand de Tönnies, porém avança no sentido de questionar uma divisão exata entre as relações comunitárias e as sociais, uma vez que considera que a maioria das relações sociais participa em parte da comunidade e em parte da sociedade. "Toda relação social, mesmo aquela mais estritamente originada na persecução racional de algum fim, pode dar lugar a valores afetivos que transcendem os simples fins almejados" (WEBER, 1973, p. 141).

Dessa maneira, Weber (1973) entende que o conceito de comunidade é deliberadamente amplo e, portanto, abrange situações muito heterogêneas. Entretanto, indica duas pistas para sua utilização. A primeira é entender o sentido de comunidade como uma contraposição radical da luta, ou luta e comunidade como conceitos relativos.

Isto não deve, entretanto, nos enganar sobre o fato completamente normal de que mesmo nas comunidades mais íntimas haja pressões violentas de todas as espécies [...]. Por outro lado, as sociedades são com freqüência (sic) unicamente meros compromissos entre interesses em jogo [...] (WEBER, 1973, p. 141-142).

A segunda diz respeito à participação dos sujeitos sociais. Segundo Weber (1973), nem toda participação comum em determinadas qualidades da situação ou da conduta implica uma comunidade. "Comunidade só existe propriamente quando, sobre a base desse sentimento, a ação está reciprocamente referida [...] e na medida em que esta referência traduz o sentimento de formar o todo (WEBER, 1973, p. 142).

A questão é que a comunidade inteiramente autossuficiente e localizada (espacial e temporariamente) que ambos os autores, de certa maneira, descrevem pertence ao mundo 
primitivo. De lá para cá ocorreram mudanças, especificamente o aperfeiçoamento dos meios de transporte e comunicação no qual está baseado o processo de globalização. Bauman (2003) reconhece que a partir do momento em que a informação passa a viajar independente de seus portadores e numa velocidade muito além da capacidade dos meios mais avançados de transporte (como no contexto da modernidade líquida, a fronteira entre o "dentro" e "fora" não pode mais ser estabelecida e muito menos mantida. Nesse sentido, o autor propõe o conceito de identidade como "substituto" de comunidade:

[...] para oferecer um mínimo de segurança e assim desempenhar uma espécie de papel tranquilizante e consolador, a identidade [...] precisa invocar o fantasma da mesmíssima comunidade a que deve substituir. A identidade brota entre os túmulos das comunidades, mas floresce graças à promessa da ressurreição dos mortos. (BAUMAN, 2003, p. 20).

Assim, "identidade" acaba por significar "aparecer": ser diferente e, por essa diferença, ser singular. Seu principal objetivo, ao contrário do que pode indicar inicialmente, não é dividir, separar ou classificar, mas agrupar, identificar, representar, ainda que tal agrupamento não seja estático, homogêneo e perpétuo no contexto espacial e temporal ilimitado. É nesse sentido que Bauman (2003) apresenta o conceito de "identidade cabide". Segundo o autor, a vulnerabilidade das identidades individuais e a precariedade da solitária construção da identidade levam o sujeito a procurarem cabides para que possam, em conjunto, pendurar seus medos e ansiedades individualmente experimentados e, depois disso, realizar os ritos de exorcismo em companhia de outros indivíduos também assustados e ansiosos (BAUMAN, 2003, p. 21).

Um dos grandes estudiosos da questão da identidade na contemporaneidade é Stuart Hall. O autor (2005) diz que para compreendermos como as identidades funcionam, precisamos conceituá-las e dividi-las em suas diferentes dimensões. Tal processo envolve o exame dos sistemas classificatórios que mostram como as relações sociais estão organizadas e divididas (geralmente em oposição: nós/eles).

De acordo com Hall (2005), com frequência, a identidade envolve reivindicações essencialistas sobre quem pertence e quem não pertence a um determinado grupo identitário, nas quais a identidade é vista como fixa e imutável. Elas são, na verdade, relacionais. A diferença é estabelecida por uma marcação simbólica relativamente a outras 
identidades. A marcação simbólica é o meio pelo qual damos sentidos a práticas e a relações sociais, definindo, por exemplo, quem é incluído/excluído.

[...] a identificação é construída a partir do reconhecimento de alguma origem comum ou de características que são partilhadas com outros grupos ou pessoas, ou ainda a partir de um mesmo ideal. É em cima dessa função que ocorre o natural fechamento que forma a base da solidariedade e da fidelidade do grupo em questão. (HALL, 2005, p. 106).

Assim, completa Hall (2005), o social e o simbólico se referem a dois processos diferentes, mas cada um deles é necessário para a construção e a manutenção das identidades. Ao mesmo tempo em que marcam algumas diferenças, tornam obscuras outras. Revelam relação de poder e discrepâncias internas: as identidades não são unificadas; podem haver contradições no seu interior que precisam ser negociadas construídas no nível coletivo e o nível individual.

Utilizo o termo 'identidade' para significar o ponto de encontro, o ponto de sutura, entre, por um lado, os discursos e as práticas que tentam nos 'interpelar', nos falar ou nos convocar para que assumamos nossos lugares como os sujeitos sociais de discursos particulares e, por outro lado, os processos que produzem subjetividades, que nos constroem como sujeitos aos quais se pode 'falar'. (HALL, 2005, p. 111-112).

O fato é: comunidade e identidade são conceitos construídos em um sistema de representação. "A representação determina a definição que nos damos e o lugar que ocupamos dentro de um certo sistema de relações" (SODRÉ, 1999, p. 35). Tal representação é construída não só a partir da natureza do sujeito (étnica, racial, relações de parentesco etc.), mas, também envolve:

a) a experiência do sujeito e suas condições sociais e materiais. Segundo Sodré (1999), a identidade liga o sujeito a um quadro de referência e promove uma intersecção entre história individual e do grupo com o qual convive, o que leva a um reconhecimento social de si mesmo no outro. A partir da identidade individual também se criam outras (o conceito de identidade-cabide de Bauman), fazendo com que a ideia de grupo seja imposta como a de um outro lugar, onde o indivíduo se sente pluralmente permitindo a tomada de uma consciência de sua identidade; 
b) um nível psíquico, ou seja, alguma versão essencialista do passado do sujeito, uma história reconstruída por meio da memória ou, na prática, aquilo que nos lembramos e que tem algum significado na nossa constituição enquanto ser individual e social. "A necessidade de memória é uma necessidade da história" (NORA, 1993, p. 14).

Tal memória, nesse contexto da criação de identidades comunitárias, pode ser individual, coletiva ou ambas. Para Halbawachs (2006), conforme o sujeito participa de um ou de outro modo de memória, adota duas atitudes diferentes e até opostas. Por um lado, suas lembranças teriam lugar no contexto de sua personalidade ou de sua vida pessoal - as mesmas que lhes são comuns com outras só seriam vistas por ele apenas no aspecto que o interessa enquanto se distingue dos outros. Por outro lado, em certos momentos, o sujeito seria capaz de se comportar simplesmente como membro de um grupo que contribui para evocar e manter lembranças impessoais, na medida em que estas interessam ao grupo.

A memória coletiva, ao contrário, é o grupo visto de dentro e durante um período que não ultrapassa a duração média da vida humana, que de modo geral, lhe é bem inferior. Ela apresenta ao grupo um quadro de si mesma que certamente se desenrola no tempo, já que se trata de seu passado, mas de tal maneira que ele sempre se reconheça nessas imagens sucessivas. A memória coletiva é um painel de semelhanças, é natural que se convença de que o grupo permaneça, que tenha permanecido o mesmo porque ela fixa sua atenção sobre o grupo e o que mudou foram as relações ou contatos do grupo com os outros. (HALBAWACHS, 2006, p. 109).

\section{Mídia comunitária: características e funções}

A classificação de veículos de comunicação em mídia comunitária não é um processo simples. Peruzzo (2003) diz que essa dificuldade principal advém da impossibilidade de delimitar os "objetos" comunitários em fronteiras claramente demarcadas, ou seja, a "comunidade não pode ser confundida simplesmente com um bairro, uma cidade ou segmentos étnicos, religiosos, acadêmicos etc. [...]. Ela pressupõe a existência de elos mais profundos e não meros aglomerados humanos" (PERUZZO, 2003, p. 55).

Na prática, algumas das configurações da mídia comunitária se misturam com as de outros tipos de mídia, especialmente a local, que por sua vez podem apresentar pontos em comum com aquela de caráter comunitário, o que acaba por gerar dificuldades de compreensão e de diferenciação entre os processos de mídia comunitária e mídia local. (PERUZZO, 2006, p. 143). 
Já Raquel Paiva (1998) destaca a interdisciplinaridade que a elaboração e a explicação do conceito de comunidade exigem, enfatizando que as premissas levantadas para desenhá-lo precisam ser pautadas por considerações oriundas não só do campo da Comunicação Social, mas também da Sociologia, Antropologia, Psicologia, Política, Religião, Ecologia, entre outras áreas.

\begin{abstract}
Uma coletividade é definida como comunidade quando seus membros agem reciprocamente, e no confronto com o outro, não pertencente à coletividade, contrapõem de maneira mais ou menos enfática seus valores, normas e costumes. Enfim, os interesses considerados são os da comunidade, dos indivíduos como um todo. (PAIVA, 1998, p. 123).
\end{abstract}

Na verdade, é a configuração de cada realidade específica que serve de parâmetro para a compreensão do significado comunitário de cada experiência de comunicação (PERUZZO, 2003, p. 249). No entanto, é possível observar alguns aspectos que tornam o percurso de mapeamento e classificação desses veículos um pouco mais sistematizado.

Segundo Paiva (1998), a mídia comunitária constitui uma força contra-hegemônica no campo comunicacional; atua em direção a uma estrutura polifônica; produz novas formas de linguagem; capacita-se para interferir no sistema produtivo; gera uma estrutura mais integrada entre consumidores e produtores da mensagem; atua também com o propósito de educação e capacitação dos envolvidos; entre outras características:

[...] cada vez mais e de forma mais agressiva, impõem-se a necessidade de se reinterpretar o conceito de comunicação comunitária. E esta é uma perspectiva animadora, porque se percebe que há em cursos formas diferenciadas de compreensão e de conceituação. (PAIVA, 2007, p. 137).

Já Peruzzo (2006) coloca algumas questões de ordem prática. Segundo a autora, a mídia comunitária tem como objetivo divulgar assuntos das comunidades, de movimentos coletivos e de segmentos populacionais ou do interesse público que normalmente não encontram espaço na mídia convencional. Além disso: os produtores das mensagens não são necessariamente especialistas (profissionais de comunicação), mas cidadãos comuns; tem como meta contribuir para o desenvolvimento comunitário como forma de ampliar o exercício da cidadania e não o lucro (daí o motivo de trabalhar com "apoio cultural" e não com anúncios publicitários); e tem gestão e propriedade coletivas e busca autonomia em relação a governos e outros grupos de interesse. 


\section{A comunicação no cotidiano da comunidade, na construção das identidades e na preservação da memória}

Nos artigos analisados neste trabalho, os conceitos de comunidade, identidade e memória são construídos na realidade dos projetos registrado nessas pesquisas por meio do discurso dos autores. Dessa maneira, a partir da aplicação do protocolo de análise (Quadro 1) sobre esses estudos, procuramos entender como tais conceitos ganham definições e contornos em uma proposta de lógica inversa à comumente utilizada no ambiente acadêmico: no lugar de entender como conceitos se aplicam e explicam processos de mídia comunitária, indicar, a partir da prática da comunicação comunitária, como esses conceitos podem ser utilizados e construídos.

Quadro 1 - Protocolo de análise

\begin{tabular}{|c|c|c|c|c|c|c|c|c|c|c|}
\hline \multirow[b]{3}{*}{ Projeto } & \multirow[b]{3}{*}{$\begin{array}{c}\text { Locali- } \\
\text { zação }\end{array}$} & \multirow[b]{3}{*}{ Autores } & \multicolumn{8}{|c|}{ Mídia Comunitária } \\
\hline & & & \multicolumn{2}{|c|}{ Tipo } & \multicolumn{6}{|c|}{ Objetivo } \\
\hline & & & Tradicional & Virtual & Visibilidade & Celebração & $\begin{array}{c}\text { Mobilização } \\
\text { / } \\
\text { Participação } \\
\text { social }\end{array}$ & $\begin{array}{c}\text { Prestação } \\
\text { de } \\
\text { serviços }\end{array}$ & Reivindicação & Outros \\
\hline
\end{tabular}

\begin{tabular}{|c|c|c|c|c|c|}
\hline \multicolumn{2}{|c|}{ Identidades } & & \multicolumn{2}{c|}{ Memória } \\
\hline Marcação simbólica & Organização & $\begin{array}{c}\text { Condição social e } \\
\text { material }\end{array}$ & Individual & $\begin{array}{c}\text { Coletiva } \\
\text { (social) }\end{array}$ & $\begin{array}{c}\text { Formas de } \\
\text { registro }\end{array}$ \\
construção do grupo & & Significado para \\
\hline
\end{tabular}

Fonte: Elaborado pelos autores.

Importante esclarecer que tal protocolo de análise foi elaborado como instrumento para sistematização do corpus. Assim, as categorias pensadas foram fixadas com base em aspectos práticos de um sistema de organização do material, bem como com base nos objetivos deste artigo, da seguinte maneira:

a) projeto, localização e autores - procuram identificar nos artigos analisados qual o projeto de mídia comunitária objeto do estudo, em que artigo se encontrava ("localização") e o nome do(s) autor(es) da pesquisa;

b) mídia comunitária - compreende as categorias "Tipo" e "Objetivo". Na primeira, a proposta foi pontuar o tipo de mídia comunitária que estava sendo estudada no artigo (tradicional: TV, Rádio e Jornal; ou virtual: websites, blogs, redes sociais, podcasts etc.). Na segunda, identificar qual o principal objetivo do conteúdo 
produzido, entre: visibilidade, celebração, mobilização e participação social, prestação de serviços, reivindicação, outros;

c) identidade - a partir da análise do veículo feita pelo autor do artigo presente no nosso corpus, o objetivo com essa categoria foi mapear quais são os marcadores simbólicos, a organização e as condições sociais e materiais do grupo responsável pela prática comunicacional envolvida;

d) memória - essa categoria serviu para identificar como o registro da história do grupo, seus hábitos, costumes e tradições. apareceram durante a produção do veículo, se a ênfase foi em uma história individual ou coletiva, quais as formas de registro, bem como seus significados para a construção do grupo.

\subsection{Sobre comunidade}

Consideramos com essa categoria que a comunidade, conforme visto nas seções 2 e 3 deste artigo, não é física ou material, mas, sim, de ordem subjetiva - um sentimento que é construído a partir das experiências do cotidiano, pelos sujeitos envolvidos e suas relações e trocas simbólicas. Tal sentimento é responsável pela geração de vínculos e laços sociais, pela possibilidade de participação, pertencimento, entre outros fatores.

Assim, de acordo com o protocolo de análise, procuramos identificar a questão da comunidade a partir de cinco categorias principais (visibilidade, celebração, prestação de serviços e reivindicação), nas quais classificamos o conteúdo produzido pelos veículos estudados pelos autores dos artigos. Verifica-se no corpus, de maneira geral, o comprometimento dos grupos envolvidos - ainda que em caráter inconsciente - em criar o sentimento comunitário a partir da retratação da realidade do cotidiano nos seus diferentes tipos de mídia.

Nesse sentido a comunidade parece ser construída, em um primeiro momento, a partir do local e do território físico. Entretanto, ganha outra dimensão valorativa ao ser retratada por meio do conteúdo abordado nos veículos: a história de moradores, suas expressões artísticas (música, dança), a realização de eventos e cursos locais, a prestação de serviços, os projetos desenvolvidos, as vagas de emprego, as denúncias e reclamações. É nesse momento, nos quais esses temas surgem e são direcionados a realidade envolvida, que se fortalecem os vínculos e laços sociais, além de sentimentos de pertencimento e participação. 
É a partir dessa produção que outras características de comunidade - que não a violência, a miséria e a exclusão, por exemplo - ganham visibilidade, e ela passa a ter visibilidade e voz. Como ilustração, citamos o projeto Voz da Comunidade (Alemão), PPG Informativo (Pavão, Pavãozinho e Cantagalo), Rocinha em Foco, Nova Paraisópolis, Morro da Cruz (DJs), Restinga, Portal Viva Favela, Central Única das favelas, Observatório das favelas (Maré), todos objetos de estudo dos artigos analisados.

Essa luta pela voz e identificação entre tantos outros sistemas de representação social é fundamental para que reivindicações do grupo (infraestrutura local, educação, saúde etc.) sejam atendidas. Não há comunidade sem luta; assim como não há comunidade sem celebração. Daí as festas e eventos destacados na análise constituirem um caminho para a valorização do estar junto.

\subsection{Sobre identidade}

Dividido em quatro categorias (marcação simbólica, organização, condição social/material e observação), o protocolo "identidade" da Análise de Conteúdo (AC) realizada procurou, à luz do conceito de identidade de Stuart Hall, brevemente discutido acima, reconhecer as origens comuns e as características partilhadas pelos grupos identitários representados pelos projetos de comunicação comunitária aqui investigados. Tratou-se de tentar pontuar um determinado grau de pertencimento, permitindo que cada indivíduo do grupo se identifique como agente, no grupo do "nós", em oposição ao grupo do "eles", possibilitando o estabelecimento da marcação simbólica percebida e relacionada a outras identidades diferenciadas.

Nota-se no corpus analisado uma predominância acentuada de atuação desses projetos para um público jovem, social e economicamente vulnerável. São grupos majoritariamente formados por estudantes de escolas públicas, moradores de favelas e zonas periféricas, quilombolas e indígenas, assentados, população rural e de migrantes.

É possível detectar, em todos os projetos analisados e conforme Peruzzo (2003; 2006) e Paiva (1998; 2007) indicam, a participação dos moradores na organização de tais iniciativas práticas de mídia comunitária, seja como planejadores, como comunicadores e fontes de informação ou ainda como audiência ativa. Exemplo disso é o projeto Rádio Cantareira FM, objeto de estudo de um dos artigos analisados, que nasceu da necessidade de comunicação no contexto popular da periferia noroeste da cidade de São Paulo e que 
estimulou a formação de uma associação formalmente institucionalizada um ano depois - a Associação Cantareira, que passou a ser responsável pela rádio e desenvolve outros projetos na área de Comunicação e Educação.

Além disso, a atuação de organizações sociais estabelecidas nas comunidades beneficiadas pelos veículos desenvolvidos é uma constante, muitas vezes verificada como condição para o fortalecimento identitário de tais grupos, a partir de uma proposta de organização que passa pela Comunicação. Como exemplo, citamos o projeto $A$ sirene - para não esquecer, criado por moradores da cidade de Mariana (MG) após o rompimento da barragem, em $2015^{1}$ - também objeto de estudo de um dos artigos do nosso corpus. Até então, não havia uma identidade única que unisse os moradores. Ela surgiu a partir da tragédia socioambiental e da mobilização da igreja católica, via arquidiocese de Mariana, junto aos moradores, por soluções para os problemas causados.

Às vezes, a mobilização da comunidade se dá a partir de órgãos externos, que não sejam, necessariamente, organizações sociais. O Conselho Nacional de Desenvolvimento Científico e Tecnológico (CNPq) apoia - via fomento de pesquisa universitária - projeto na região do Crato (CE); o Poder Legislativo do Estado do Pará investe no projeto Tela Firme, na produção de programa de TV na periferia de Belém. A Funai apoia o Clube de Comunicação Popular, em Dourados (MS), e o governo federal é a base do programa desenvolvido em Duque de Caxias, o Imbariê - todos objetos de estudo do corpus aqui reunido. Cabe à iniciativa privada também, subsidiar programas - como vimos em um dos artigos analisados, no caso de jovens da favela de Heliópolis (cidade de São Paulo) apoiados pela Ambev.

Assim, podemos dizer que a construção de uma identidade coletiva passa pelo processo de participação, constituído pela experiência dos sujeitos em grupo, para além de suas condições sociais, econômicas, políticas e culturais. Trata-se de uma intersecção entre as histórias individuais desses agentes comunicacionais com a do grupo de convivência, criando-se assim um canal para o reconhecimento identitário.

\footnotetext{
${ }^{1}$ No dia 5 de novembro de 2015, o rompimento da barragem de Fundão, da mineradora Samarco, deixou 19 mortos e causou uma enxurrada de lama que inundou várias casas no distrito de Bento Rodrigues, em Minas Gerais, causando, além de mortes e destruições, um dos maiores desastres ambientais do Brasil.
} 


\subsection{Sobre memória}

Colocamos a questão da memória no protocolo de análise, dividindo-a em três categorias principais (memória individual ou coletiva, formas de registro e significado para a constituição do grupo). 0 objetivo foi entender, baseado em Nora (1993) e Halbawachs (2006), como a questão da memória (individual ou coletiva) pode contribuir para a necessidade de história do grupo envolvido, bem como sua formação identitária, representado nas estratégias de comunicação criadas.

Verifica-se que os veículos e ações produzidos, independentemente do formato, grupo envolvido, localização, etc., contribuem para a construção e registro da memória coletiva do grupo, podendo em alguns casos colaborar ainda para a memória individual. Um exemplo dessa situação é o projeto "Eu, empregada doméstica", conforme artigo analisado, que serve para registro de relatos pessoais, compondo a memória individual do sujeito envolvido. Outro caso é o boletim impresso O Candeeiro, do Ceará. Ele pode servir de instrumento para o registro das experiências das famílias de agricultores locais no trabalho no campo.

O registro da memória costuma se materializar no veículo noticioso produzido, na forma de conteúdo. Observa-se também a importância do acesso às Tecnologias de Informação e Comunicação (TICs) no registro das memórias. O corpus analisado revelou praticamente todas as possibilidades, desde spots gravados para rádios comunitárias e websites até histórias em quadrinho, passando ainda por fotos, vídeos e textos. Por se tratar de grupos vulneráveis, os custos para implementação desses projetos ficam distante do alcance de todos. Assim, é frequente a utilização de meios de comunicação mais acessíveis economicamente.

Sobre o conteúdo dessas memórias, a forma de registro é múltipla, destacando o papel da mídia comunitária na criação de novos formatos, como indicado por Paiva (1998; 2007) e Peruzzo $(2003 ; 2006)$ anteriormente. Alguns formatos verificados no corpus foram: música, poesia, histórias em quadrinho, contos, imagens, relatos, notícias e desenhos. Outra observação é que o registro pode ser feito utilizando mais de uma língua. É o caso do projeto Clube de Comunicação Popular, de Dourados (MS), e da rádio Rebelde Zapatista, do México, ambas experiências estudadas nos artigos analisados. 0 primeiro se utiliza dos idiomas falados nas aldeias indígenas de Bororó, Jaguapiru e Panambizinho; o segundo contempla 
locução de contos, poesias e músicas, entre outras linguagens, bilíngue (espanhol e língua originária - tsotsel e tseltal).

\section{Considerações finais}

Conforme esperado, os conceitos de comunidade, identidade e memória se revelaram plurais e elásticos na compreensão dos processos sobre a prática comunitária, evidenciando o campo da Comunicação - especificamente a prática da comunicação comunitária - como protagonista de processos como afirmação, semelhança e pertencimento. Esses três termos aliados à mobilização se tornam palavras-chave nesse contexto; mas não únicas. Convivência, solidariedade, movimentação em torno de uma causa comum e integração não podem, de maneira nenhuma, virem separados do verdadeiro sentimento comunitário.

Nesse sentido, é difícil precisar se o sentido comunitário é construído antes ou depois da decisão de se produzir um veículo nos moldes analisados neste trabalho. Arriscamos a dizer que é um processo de construção conjunto, que ocorrem em paralelo e de forma simultânea, no qual as experiências cotidianas ganham dimensões de ordem afetiva, vinculativa e identitária na medida em que são transpostas para o conteúdo dos jornais, emissoras de rádio, websites e outros formatos evidenciados.

Tais dimensões revelam, ainda, um aspecto histórico da realidade envolvida, uma vez que, tais veículos comunitários, criados pela ação coletiva, são, também, preservados pela memória do grupo. E cabe à Comunicação a responsabilidade de revelar essa realidade, com destaque para como conceitos podem ser construídos a partir da prática. Nesse sentido, é apropriado registrar que conceitos como comunidade, identidade e memória ganharam outros contornos, funções e evidências.

Sodré $(1999 ; 2014)$ diz que o desafio epistemológico da área da Comunicação é construir um paradigma de conhecimento em que o discurso reflexivo não seja totalmente estranho ao senso comum dos agentes sociais da Comunicação, expresso tanto na mídia quanto na diversidade de práticas culturais. Assim, vemos outras possibilidades para a visibilidade de um "ecossistema existencial em que a comunicação equivale a um modo geral de organização" (SODRÉ, 2014, p. 25). 


\section{Referências}

BARDIN, L. Análise de conteúdo. Lisboa: Edições 70, 1977.

BAUMAN, Z. Comunidade: a busca por segurança no mundo atual. Rio de Janeiro: Jorge Zahar Editor, 2003.

HALBWACHS, M. A memória coletiva. São Paulo: Vertice, 1990.

HALL, S. A identidade cultural na pós-modernidade. Rio de Janeiro: DP\&A Editora, 2005.

KRIPPENDORFF, K. Metodologia de Analisis de Contenido. Barcelona: Ediciones Paidós, 1990.

PAIVA, R. 0 espírito comum - Comunidade, mídia e globalismo. Petrópolis: Vozes, 1998.

PAIVA, R. Para interpretar a comunicação comunitária. In: PAIVA, R. 0 retorno da comunidade: (os novos caminhos do social). Rio de Janeiro: Mauad X, 2007. p. 133-148.

PERUZZO, C. M. K. Mídia Local e Suas Interfaces com a Mídia Comunitária. Anuário UNESCO/UMESP de Comunicação Regional. São Bernardo do Campo: Cátedra Unesco/UMESP, 2003.

PERUZZO, C. M. K. Mídia local e suas interfaces com a mídia comunitária no Brasil. In: Anuário Internacional de Comunicação Lusófona. São Paulo: LUSOCOM, 2006, 4, p. 141162.

PERUZZO, C. M. K.; OTRE, M. A. C.. (org.). Comunicação Popular, Comunitária e Alternativa no Brasil: Sinais de resistência e de construção da cidadania. São Bernardo do Campo: Editora Metodista, 2015.

NORA, P. Entre memória e história: A problemática dos lugares. Projeto História. Revista do Programa de Estudos Pós-Graduados em História e do Departamento de História da PUC-SP, São Paulo, 1993, 6, p. 6-28.

SODRÉ, M. Claros e escuros: identidade, povo e mídia no Brasil. Petrópolis: Vozes, 1999.

SODRÉ, M. A ciência do comum - Notas para um método comunicacional. Petrópolis: Vozes, 2014.

STUMPF, I. R. C. Pesquisa bibliográfica. In: DUARTE, Jorge; BARROS, A. (Orgs.). Métodos e Técnicas de Pesquisa em Comunicação. São Paulo: Atlas, 2011. p. 51-61.

TÖNNIES, F. Comunidade e Sociedade como entidades típico-ideais. In: FERNANDES, F.

(Org.). Comunidade e sociedade: leituras sobre problemas conceituais, metodológicos e de aplicação. São Paulo: Editora Nacional e Editora da USP, 1973. p. 96-116. 
WEBER, M. Comunidade e sociedade como estruturas de socialização. In: FERNANDES, F (Org.). Comunidade e sociedade: leituras sobre problemas conceituais, metodológicos e de aplicação. São Paulo: Editora Nacional, 1973. p. 140-143.

\title{
The building of community, identity and memory concepts from the practice of community communication
}

\begin{abstract}
This article aims to verify how, based on community media initiatives, the concepts of community, identity and memory are configured. The proposal starts from an opposite perspective to the ordinary logic used: instead of bringing concepts to explain empirical realities, it seeks to verify how the concepts are built from experiences. For this, we propose a Content Analysis, with a qualitative approach, on a corpus composed by 30 academic articles published in scientific events and books in the Social Communication field, which register experiences of community media. Among the main results, we highlight that the daily experiences of a community "translated" by its vehicles, as well as by the production practice of these vehicles, show affective, binding, identity and historical dimension of the group involved, in which concepts of community, identity and memory gain other outlines, functions and evidence.
\end{abstract}

\section{Keywords}

Community media; Memory; Identity; Community; Social Communication

\section{Autoria para correspondência}

Camila Escudero

camila.escudero@metodista.br

\section{Como citar}

ESCUDERO, Camila; CAETANO, Lucia; REINA, Eduardo. A construção dos conceitos de comunidade, identidade e memória a partir da prática da comunicação comunitária. Intexto, Porto Alegre, n.52, e97056, jan./dez. 2021. DOI: http://dx.doi.org/10.19132/1807-8583202152.97056

Recebido em 30/09/2019

Aceito em 28/05/2021

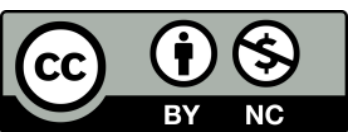

